\title{
El travestismo fotográfico de Yasumasa Morimura: un ejemplo de parodia y anacronismo en el arte contemporáneo*
}

\author{
Constanza Navarrete \\ Universidad de Chile \\ constanzanavarretew@gmail.com
}

\begin{abstract}
Resumen
El artista japonés Yasumasa Morimura suele apropiarse de obras famosas de la historia del arte occidental, mediante fotografías donde figura reemplazando a los personajes femeninos retratados a través de una puesta en escena con disfraces, maquillaje y accesorios. De este modo, sus montajes alteran la pintura o fotografía original, incluyendo también otros elementos para resignificar la obra de referencia parodia mediante el humor y la crítica. Esta estrategia es utilizada por numerosos artistas contemporáneos que combinan estéticas y visiones de distintos momentos históricos, aludiendo a un cierto anacronismo acaso indisociable del concepto de parodia.
\end{abstract}

Palabras clave

Yasumasa Morimura, arte contemporáneo, montaje fotográfico, parodia, anacronismo.

\section{The photographic transvestism of Yasumasa Morimura: an example of parody and anachronism in contemporary art}

\begin{abstract}
Japanese artist Yasumasa Morimura often appropriates famous works from Western art history by staging photographs where he uses costumes, makeup and other accessories to replace female characters. His montages alter the original painting or picture in order to resignify the referenced work through humor and criticism. This strategy is used by many contemporary artists who combine aesthetics and visions of different historical moments, alluding to a certain anachronism that, perhaps, is inseparable from the concept of parody.
\end{abstract}

Keywords

Yasumasa Morimura, contemporary art, photomontage, parody, anachronism.

* Recibido: 14 de marzo de 2017/ Aceptado: 22 de noviembre de 2017. 


\title{
O travestismo fotográfico de Yasumasa Morimura: um exemplo de paródia e anacronismo na arte contemporânea
}

\begin{abstract}
Resumo
O artista japonês Yasumasa Morimura normalmente se apropria de obras famosas da história da arte ocidental, através de fotografías onde ele substitui as personagens femininas retratados por meio de uma encenação com trajes, maquiagem e acessórios. Assim, suas montagens mudam a foto ou a pintura original, incluindo também outros elementos para resignificar a obra de referência através do humor e crítica. Esta estratégia é usada por muitos artistas contemporáneos que combinan estética e visões de diferentes momentos históricos, aludindo a um certo anacronismo inseparáveis, tal vez, do conceito de paródia.
\end{abstract}

\section{Palavras-chave}

Yasumasa Morimura, arte contemporânea, fotomontagem, paródia, anacronismo. 


\section{Introducción}

Este artículo reflexiona sobre algunas manifestaciones del arte contemporáneo, asociadas al concepto de parodia y su consecuente anacronismo. En primera instancia se analizará el término de arte contemporáneo; qué implica y cómo se manifiesta en diversas obras, basándose en los postulados de algunos teóricos tales como Arthur Danto, Jacques Rancière, Nicolás Bourriaud, Frederic Jameson, Jean Baudrillard, entre otros, para luego entrar a definir lo que son la parodia y el anacronismo. Ahora bien, ¿por qué vincular ambos términos en apariencia disímiles? Como podremos observar a través del texto, tanto la parodia como el anacronismo pueden coexistir dentro de una obra o propuesta artistica. En este caso, es la producción del japonés Yasumasa Morimura la que se toma como ejemplo para poner en relación estos conceptos típicos de la posmodernidad; contexto en el que operaciones tales como la cita, la ironía y el cruce temporal parecen haber desplazado a las utopías y meta-relatos de la modernidad como sustentos de las obras. Para ello se discutirán cuatro fotografías del artista: "Portrait (Futago)" de 1988; "To My Little Sister: for Cindy Sherman" (1998), "After Marilyn Monroe" (1997) y "Black Marilyn" (1996).

En ese sentido, los objetivos de esta investigación son discutir diferentes acepciones tanto de arte contemporáneo como de parodia y anacronismo, estableciendo cruces para lograr acercarse a ciertas prácticas y modos de operar en el arte contemporáneo, sin limitar la posibilidad de otras lecturas.

\section{¿Cómo definir el arte contemporáneo?}

El llamado arte contemporáneo es un término ampliamente utilizado hoy en día para referirse sobre todo a lo que es arte actual. Sin embargo, ¿debemos entenderlo como una mera categoría cronológica del arte reciente? Para diversos teóricos, entre ellos Arthur Danto (1999), el concepto de arte contemporáneo trascendería esa categoría del presente asociado a los últimos años, por lo cual se le analiza desde una perspectiva histórica, estética y filosófica.

Danto realiza una distinción entre los conceptos de moderno y contemporáneo en su libro Después del fin del arte. Para el modernismo, la cuestión de la representación era el tema central: se trascendía el previo canon de la mímesis o representación imitativa del mundo visible para alcanzar cada vez más su pureza ${ }^{1}$.

\footnotetext{
${ }_{1}^{1}$ Para definir el modernismo, Danto se basa en gran medida en los postulados del crítico de arte Clement Greenberg (basado en su ensayo de 1960, "Pintura modernista"), a quien considera como el principal narrador del modernismo. Para Greenberg, el arte maduro y en tanto puro, es aquel arte que se ocupa del arte mismo y su sistema formal de representación; noción que deja fuera a vanguardias como el surrealismo o dadaísmo, que serían impuras.
} 
En ese sentido, el arte moderno operó como una ruptura respecto a la historia del arte, pues fue un corte a partir del cual utópicamente se buscaba comenzar de nuevo, superando al pasado y planteando nuevas formas e incluso teorías en torno a la obra de arte, su concepto de belleza y su función. Por el contrario, el arte contemporáneo -supuestamente- no reniega del arte del pasado, sino que dispone de él para su libre uso y apropiación. Bajo esa premisa, Danto califica el arte contemporáneo como posthistórico, pues prácticamente todo le estaría permitido, sin tener que subordinarse a un orden, relato o regla establecida para la creación. En sus palabras: "no hace un alegato contra el arte del pasado (...) En cierto sentido lo que define al arte contemporáneo es que dispone del arte del pasado para el uso que los artistas le quieran dar" (1999: 27). De ahí se desprende su tesis del fin del arte -compartida también por otros teóricos como Theodor Adorno y G. W. F. Hegel (cit. Cubo, 2010) ${ }^{2}$. No obstante, no es un fin del arte en sentido literal, en cuanto al cese de su producción a nivel global o de su circuito, institucionalización y mercado, ya que, de hecho, éstos continúan existiendo sin aparente problema -incluso cada vez más prolífico-, sino que refiere más bien al fin del relato establecido, definido, unificado y consecuente con un estado antecesor del arte.

A su juicio, este cambio de paradigma que daría origen al nuevo concepto de arte contemporáneo ocurrió alrededor de los años setenta, época en que surgieron variados estilos, como el pop art, op art, minimalismo, arte povera, nueva escultura, land art y arte conceptual, entre otros, que no distinguían necesariamente a la obra de arte de un objeto o cosa real, vale decir, común y corriente. Esta tesis, Danto la ejemplifica con las cajas Brillo de Andy Warhol, en las que no habría diferencia visible con relación a las del supermercado, generando la pregunta siguiente: ¿por qué tendría que ser ésta una obra de arte y no así la que se ve idéntica, del supermercado? El teórico concluye que la Brillo recreada por Warhol está producida y pensada dentro del marco artístico, siendo la intención y el concepto los que la validarían como obra ${ }^{3}$ según ciertas teorías, en un contexto donde yacen las consignas de que cualquier cosa puede ser arte o, según Joseph

\footnotetext{
${ }^{2}$ Para Hegel (1770-1831) la muerte o fin del arte viene asociado al contexto romántico, en donde el hombre se centra en su subjetividad, marcado por los deseos, orgullos y sentimientos que luchan dentro de sí, sin contenido o pathos que lo limite, a diferencia del arte clásico en cuanto materialización de la idea y la ética. En el caso de Theodor Adorno (1903-1969), el fin tiene que ver con la desartistización del arte, producto de la reproductibilidad técnica y la industria cultural, las que impedirían continuar hablando de obras de arte, bellas e irrepetibles.

${ }^{3}$ Aquel fenómeno también ocurrió a principios del siglo XX con los ready-mades de Marcel Duchamp, quien ponía en tela de juicio justamente el estatuto de la obra de arte y la no factura o autoría del creador, a no ser por la firma y el gesto conceptual de insertar el objeto cotidiano en el contexto museal, y de ese modo ser concebible como obra.
} 
Beuys, cualquier persona puede ser artista. Tal es el momento del fin del arte y, por tanto, la instancia para el arte contemporáneo.

El teórico y crítico argentino, Néstor García Canclini (2001), por su parte, establece una relación entre la modernidad y su trance hacia la posmodernidad como otro elemento definitorio en el arte contemporáneo, cuestión compartida por los críticos Frederic Jameson (1991) y el mismo Danto, entre otros. Si la modernidad aspiraba al progreso y la racionalización utópica, la posmodernidad se distinguiría -entre otras cosas- por la caída de los meta-relatos y fundamentalismos. Debido a ello, la posmodernidad conllevaría una hibridez, una des-colección y una desterritorialización, causando que el arte no cuente ya con bases suficientemente sólidas sobre las que sostenerse (2001), o que tome y sintetice elementos de diversa índole a modo de collage, lo cual también señala Jameson en su libro El posmodernismo o la lógica cultural del capitalismo avanzado. Este último plantea, sobre la experiencia posmodernista aplicada a las obras de arte, la idea de que la "diferencia relaciona": "la antigua obra de arte se ha transformado en un texto para cuya lectura se debe proceder mediante la diferenciación y no ya mediante la unificación" (1991: 72-73), enfatizando en su carácter heterogéneo y fragmentario. Como diría Jacques Rancière (2010), esto se realizarìa mediante el disenso en vez del consenso, en tanto enunciación subjetiva que reconfigura la experiencia común de lo sensible. Sin embargo, para Rancière el arte contemporáneo no se distingue por esa oposición moderno/posmoderno, sino por los desplazamientos entre arte y no arte, los que contribuyen a construir choques entre elementos heterogéneos, dando pie al collage ya mencionado.

Tales cruces entre arte y no arte son parte de la estética relacional característica de las prácticas artísticas contemporáneas a nivel general, de acuerdo con Nicolas Bourriaud, quien las define en base al intercambio y la intersubjetividad. Para este autor, "el arte actual muestra que sólo hay forma en el encuentro, en la relación dinámica que mantiene una propuesta artística con otras formaciones, artísticas o no" (2006: 22). En ese sentido, la obra contemporánea constituye un tiempo por experimentar, más allá de un objeto o firma, cuyo sentido es creado de manera colectiva con los espectadores. No obstante, Rancière va más allá en la teoría del arte relacional, señalando que la política del arte tiene una finalidad que no es ya "la producción de lazos sociales en general sino una subversión de lazos sociales muy determinados, aquellos que son prescritos por las formas del mercado, por las decisiones de los dominantes y la comunicación mediática" (2010: 74).

\section{Parodias en el arte contemporáneo}

La visión de Jean Baudrillard respecto del arte actual es más pesimista, pues señala que no es sino la manifestación de una desilusión radical del mundo, 
llevado a la simulación de la realidad y, en definitiva, a su banalización. Comenta: "cita, simulación, re-apropiación, el arte actual se dedica a reapropiarse de manera más o menos lúdica, más o menos kitsch, de todas las formas del pasado, cercano, lejano y hasta contemporáneo" (2006: 11), lo cual deviene en lo irónico. A partir de esta noción surge lo que se conoce como parodia en el arte contemporáneo, apreciable en la obra de numerosos artistas. Dentro de sus acepciones, podemos distinguir principalmente dos visiones: una, que la entiende como estrategia de imitación frente a un elemento u obra que, por medio de la ironía y la burla, devela una crítica; otra, que alude a una repetición, pero como un eco vacío, ya desgastado y sin fundamento.

La académica y teórica canadiense, Linda Hutcheon, ha desarrollado el tema de la parodia y su política en el contexto de la posmodernidad. Ella plantea que la parodia es efectivamente una repetición irónica del pasado, mas lejos de lo nostálgico, ahistórico o vaciado; por el contrario, mantendría siempre un carácter crítico. Afirma: "la parodia señala cómo las representaciones presentes vienen de representaciones pasadas y qué consecuencias ideológicas se derivan tanto de la continuidad como de la diferencia" (1993: 187), estableciendo así una intertextualidad, pues requiere citar un referente-obra, en este caso- pero con ciertas diferencias. No se trata simplemente de una cita, en cuanto no es una alusión con fines de homenaje -necesariamente- o nostalgia ante un determinado pasado, obra o artista. Si bien la cita es parte constitutiva de la parodia, ésta enfatiza en su aspecto irónico y con mirada crítica, no siempre de la obra que se parodia, sino del contexto histórico-cultural y sociopolítico al que alude 4 .

De ahí que Hutcheon conciba la parodia como una política de la representación, "problematizadora de los valores, desnaturalizadora, de reconocer la historia" (1993:188). Sin embargo, ante esta visión nos enfrentamos con la segunda que mencionábamos, respecto a la parodia posmoderna: aquella que no ve en ésta sino su agotamiento. Esta visión es compartida por teóricos como el estadounidense Frederic Jameson, para quien la parodia tuvo su momento durante el modernismo, de modo que lo que quedaría de ella tras la posmodernidad es solamente el pastiche, entendido como "imitación de una mueca determinada (...) pero se trata de la repetición neutral de esa mímica, carente de los motivos de fondo de la parodia, desligada del impulso satírico (...) El pastiche es, en consecuencia, una parodia vacía (...) una suerte de ironía vacía" (Jameson, 1991: 4344).

\footnotetext{
${ }^{4}$ En efecto, Hutcheon cita al crítico J.A Yunck en su libro $A$ Theory of Parody. The Teachings of TwentiethCentury Art Forms (1985), quien distingue entre las parodias que utilizan la obra o el texto parodiados como blanco -la parodia más tradicional-y aquellas que lo usan como arma, que es el sentido que nos incumbe a nosotros dentro del marco del arte contemporáneo.
} 


\section{La parodia como forma de anacronismo}

La cuestión que aflora a continuación es la de cómo conciliar estas oposiciones: ¿es posible reivindicar el sentido crítico de la parodia, más allá de la cita o pastiche/collage de temporalidades?

No obstante, hablar de parodia es ineludiblemente hablar también de superposición de tiempos, cruces epocales y contextuales de los que la parodia hace alarde, reactualizándolos en sus operaciones. Para ello, utiliza la ironía, a veces el humor o ridículo, con más o menos sarcasmo. En esa dirección podemos encontrar parodias más sutiles o respetuosas, por así decirlo, versus parodias más bien despectivas o incluso destructivas. Aún así, en ambos casos habría una intencionalidad crítica, cuyo propósito es tensionar dos tiempos: el del origen de la obra que se utiliza para parodiar y el de la obra actualizada. Esta última hace una apropiación y relectura del pasado citado con el fin de generar un nuevo sentido o cuestionamiento desde el presente que enuncia, donde pone en evidencia sus contradicciones y enfatiza sus diferencias. Según esa perspectiva, la noción de anacronía, entendida como un tiempo dislocado, contradictorio y simultáneo, nutrido de múltiples presentes, es fundamental para comprender el método paródico. Lo que parecería ser un fuera de contexto o contingencia es, en realidad, una actualización por medio de la deconstrucción. Como bien señala Georges Didi-Huberman:

Ante una imagen -tan antigua como sea-, el presente no cesa jamás de reconfigurarse (...). Ante una imagen -tan reciente, tan contemporánea como sea-, el pasado no cesa nunca de reconfigurarse (...). Pero ¿cómo estar a la altura de todos los tiempos que esta imagen, ante nosotros, conjuga sobre tantos planos? (2011: 32).

Para este autor, tanto la historia como las obras de arte no pueden existir sino desde el anacronismo, al revés del supuesto orden cronológico o lineal al que teóricamente aspiran los historiadores. Es a través del montaje -que, en otros términos, podríamos llamar collage- que se materializa, para Didi-Huberman, el anacronismo; única forma posible para la construcción de historia y también de memoria. El montaje es, por tanto, el modo de hacer visible los anacronismos y los encuentros de temporalidades heterogéneas que convergen en una obra o imagen.

En ambos casos, tanto para la anacronía como para la parodia, es posible vislumbrar una superposición temporal de ideas, estilos y modos de vida que yacen en continua resignificación: no hay realidad única, invariable ni verdadera, sino su constante devenir a través de una contemporaneidad que está siempre en tela de juicio y sometida a ulterior evaluación. En ese sentido, la post-representación es constitutiva del fenómeno posmoderno que yace desprovisto de absolutismos 
y hermetismos. En cambio, busca afirmarse a partir de las sucesivas revisiones en torno a la eventual veracidad de los relatos y las crisis de las representaciones.

\section{Yasumasa Morimura y sus puestas en escena fotográficas}

Un ejemplo de artista contemporáneo que integra este tipo de operaciones es Yasumasa Morimura (1951), artista visual de origen japonés. Su obra se caracteriza, a grandes rasgos, por apropiarse de diversas obras famosas de la historia del arte occidental, de las que él se hace parte disfrazándose y reemplazando a los personajes principales, muchas veces femeninos, a través de una puesta en escena fotográfica. El autorretrato y travestismo ${ }^{5}$ de su propio cuerpo son fundamentales a la hora de parodiar y alterar los códigos epocales de cada obra en cuestión. Juega así entre la realidad de la fotografía y la pintura o foto original ${ }^{6}$, incluyendo también otros elementos con el fin de modificar y resignificar la obra que parodia.

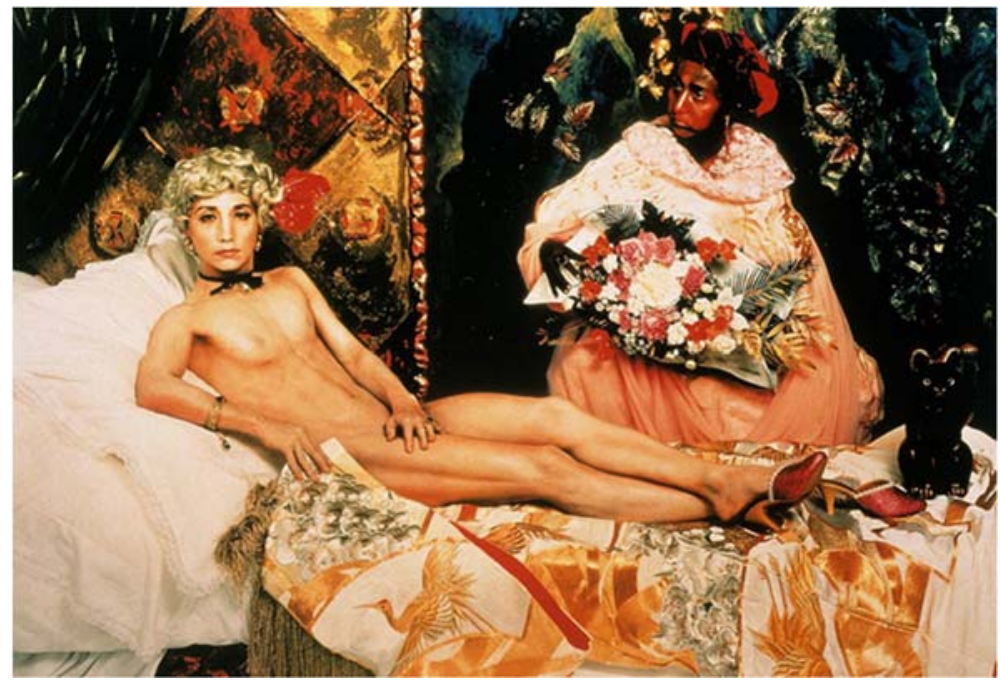

Figura 1. Yasumasa Morimura. "Portrait (Futago)". Fotografía. 1988.

\footnotetext{
${ }^{5}$ El travestismo es, en sentido literal, el acto de vestir como el sexo opuesto. Asimismo, generalmente supone adoptar actitudes y gestos del otro sexo.

${ }^{6}$ El término original, en este artículo, será aplicado como sinónimo de referencia. En ese sentido, es indistinto que se trate de una pintura o fotografía, pues no guarda relación con la técnica o medio utilizado. Por lo mismo, la discusión en torno a si la fotografía es considerada como original en cuanto obra única (dada su reproductibilidad) será irrelevante, siendo aquel tema posible de desarrollo para otro artículo.
} 


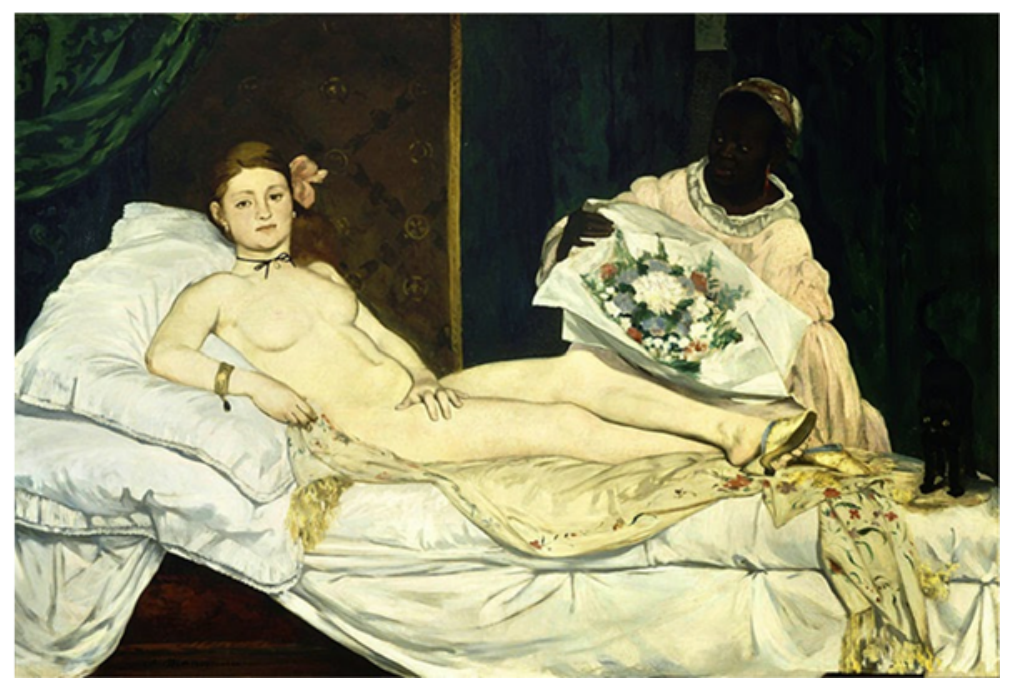

Figura 2. Edouard Manet. "Olympia". Óleo sobre tela. 1863.

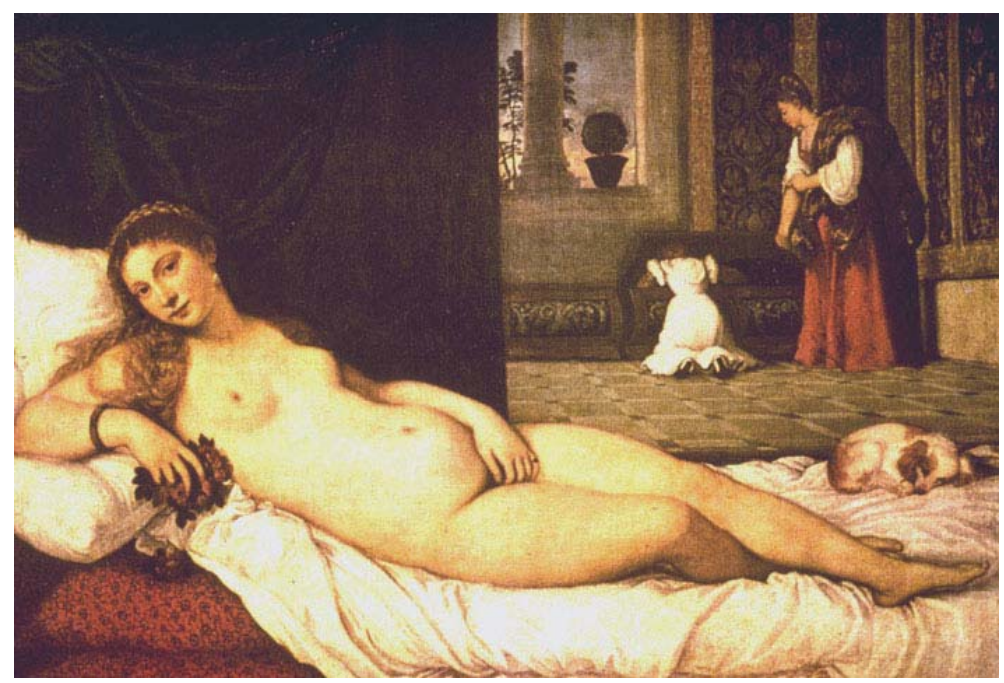

Figura 3. Tiziano. "Venus de Urbino". Óleo sobre tela. 1538.

En el caso de "Portrait (futago)" (fig.1), Morimura hace una cita paródica a la polémica obra de Edouard Manet, "Olympia" (fig. 2), del año 1863, que es a su vez, una cita a la "Venus de Urbino" de Tiziano (fig. 3), donde también aparece una mujer desnuda, acostada sobre la cama de una habitación. Sin embargo, su contexto es lo opuesto al plasmado por Manet: en Tiziano se trata de una mujer 
casada y de alta burguesía, cuya anatomía y representación pictórica obedecen a la tradición clásica. Además, a sus pies yace acostado un perrito, asociado a la fidelidad en el matrimonio.

Cabe señalar que Manet fue un artista bastante criticado en su época, pues fue un rupturista en cuanto alteró la tradición pictórica, tanto temática como técnicamente: su forma de pintar era -teóricamente-sucia y plana, eliminando el modelado o tridimensionalidad a la que aspiraba la pintura académica. Sin embargo, más allá de la técnica, "Olympia" fue motivo de escándalo porque rompía con el modelo de representación del desnudo femenino heredado por siglos, el cual se reservaba para la figura de Eva, Venus o mujeres de la aristocracia -como en el caso de "Venus de Urbino"-, abordado generalmente de manera muy sutil, ya que, a través del cuerpo, se buscaba reflejar la "belleza ideal" de acuerdo a la cosmovisión clásica. Manet en cambio, pintó un desnudo de una prostituta, mujer de carne y hueso, símbolo de lascivia y tabú social, que para colmo miraba desafiante a los ojos del espectador. De esa forma, Manet incorpora un desnudo "real", carnal, ya no idealizado ni divinizado de acuerdo al canon clásico imperante. Como señala Georges Bataille en Las lágrimas de Eros:

Manet fue el primero en apartarse resueltamente de los principios de la pintura convencional, al representar lo que realmente veía, y no lo que hubiera debido ver (...). Los desnudos de Manet tienen una brusquedad no disimulada por el ropaje de lo habitual -que deprime- ni de lo convencional -que suprime (2002: 194).

En esa dirección podríamos decir que Manet realiza una parodia respecto al género del desnudo y su representación hasta entonces, a través de la subversión pictórica de aquella prostituta. Aquel historial es recogido por Morimura, quien realiza en su obra nuevamente una ruptura y una parodia: mientras que en Manet veíamos a la imagen de una mujer, ahora tenemos en vez a la imagen del mismo Morimura. Si la noción de desnudo como forma de arte asociada al idealismo y proporciones mensurables con "Olympia" yacía corrompida -en aquel entonces, con la imagen de un hombre disfrazado de mujer esto eventualmente se potenciaría. Por lo demás, el cuerpo menudo de Morimura no está precisamente dentro del ideal de belleza masculino clásico, cayendo en la ironía burlesca. En "Portrait" lo vemos a él, simulando ser Olympia, tendido sobre una cama, desnudo, con una peluca exageradamente rubia -que contrasta ante su piel morena-, una cinta en el cuello, aros, un anillo, pulseras y zapatos con tacos. A su vez, hay una sirvienta de piel oscura, semejante a la del cuadro de Manet, llevando flores a la nueva Olympia de género masculino; indicio de ser un regalo por parte de algún cliente o amante. A los pies de la cama se encuentra el típico gato de la fortuna oriental de color negro, en reemplazo al gato negro de Manet, el cual representaba lo oculto, el engaño y traición -opuesto al perrito de Tiziano. En este caso, al tratarse de un objeto de la "suerte" adopta un significado diferente: de buen presagio, 
felicidad y abundancia. Por otro lado, el papel mural de fondo, las cortinas y mantas en la fotografía de Morimura son radicalmente distintos a los del cuadro de Manet: con colores saturados, contrastados y con diseños de motivos orientales como flores y aves, estableciendo un sincretismo entre lo occidental de la pintura referencial y lo oriental de ésta.

Podemos señalar que tanto en la fotografía de Morimura como en la pintura de Manet, se presenta una mirada crítica y paródica respecto a diferentes aspectos de sus épocas. Por un lado, Manet modifica el modo de representar el desnudo femenino, incorporando a una prostituta en la tela: mujer de carácter carnal, sin idealización física alguna, en postura de Venus acostada ${ }^{7} y$, además, empleando una técnica no académica, a diferencia de su referente renacentista (Tiziano). Morimura, por su parte, retoma la idea del desnudo, aunque esta vez desde el autorretrato y el cuerpo travestido, agregando un cuestionamiento ante la identidad de género y sexual ${ }^{8}$, las relaciones Oriente-Occidente y lo contemporáneo respecto lo moderno, así como lo moderno respecto de lo clásico/tradicional. En ambos casos, surge la pregunta acerca de quiénes deben o merecen retratarse, utilizar una de las posturas de Venus y, por tanto, erigir un modelo de belleza.

Por otra parte, más allá de esta obra puntual, hay algo de componente camp ${ }^{9}$ en aquel gesto de inversión o mezcla de géneros que realiza Morimura y que, de hecho, es una constante en sus trabajos. Umberto Eco explica que el camp se mide por su "grado de artificio y de estilización, y más que como estilo se define como capacidad de mirar el estilo de otro. En el objeto camp ha de haber cierta exageración y cierta marginalidad" (2007: 408). Otra faceta del camp, ligada a lo anterior, es el aspecto andrógino o hermafrodita de una persona, es decir, a la copresencia de ambos sexos o bien de ninguno. Con las representaciones sustitutivas de Morimura, no sólo existe artificio, sino también una importante escenificación teatral-con maquillaje, vestuario y gestualidad-en la que se reflejan ciertas características de la estética y ambigüedad sexual camp, a veces asociadas al idiolecto gay.

Morimura se ha convertido, en sus obras, en diversos personajes femeninos como Frida Kahlo, la Mona Lisa, la Joven de la perla (o la Muchacha con turbante,

\footnotetext{
${ }^{7}$ Las representaciones de la Venus en cuanto a modelo de belleza femenina y desnuda (no necesariamente de la Diosa grecolatina), solían ser de pie -en contrapposto- o acostadas.

${ }^{8}$ Tema tan en boga y debate en el último tiempo en Chile, sobre todo desde la aparición del llamado "bus de la libertad" en las ciudades de Santiago y Valparaíso en julio de 2017. El bus ponía en circulación física y simbólica la idea de hombres y mujeres como única posibilidad sexual en los humanos, mediante frases como: "Los niños tienen pene. Las niñas tienen vulva. Que no te engañen" y "Si naces hombre, eres hombre. Si eres mujer, seguirás siéndolo", lo cual generó profundas críticas y controversias.

${ }^{9}$ El camp es considerado como un tipo de gusto, estilo y/o sensibilidad que Susan Sontag desarrolló exhaustivamente en su ensayo Notas sobre lo camp, de 1964.
} 
de Vermeer), Las meninas de Velázquez, Audrey Hepburn, entre otras artistas e íconos pictóricos. Estas transformaciones físicas recuerdan al trabajo de la fotógrafa Cindy Sherman (1954, Nueva Jersey), también conocida por disfrazarse y posar ella misma en sus fotografías según diversos estereotipos de la sociedad contemporánea. Asimismo, ella ha recreado algunas pinturas de la historia del arte mediante el montaje físico y puesta en escena fotográfica. Este gesto obedece a una crítica sobre el estatuto de la mujer en el mundo actual; el feminismo, el machismo, la identidad de género y su concepción sociocultural. Para ello, ambos artistas utilizan no sólo el maquillaje y la teatralidad corporal, sino además la ironía, cierto humor e incluso la exageración y la caricaturización, acentuando la ficción y la parodia, que yace entre lo cómico y lo satírico.

No obstante, "Untitled \#96" (1981) de Cindy Sherman (fig.4), apela a otro tipo de montaje. En esta fotografía, tomada desde arriba y con formato apaisado, aparece Sherman disfrazada como una joven adolescente, tendida sobre el piso de una casa, con una posible carta en una de sus manos y mirando al fuera de campo, aparentemente reflexiva y nostálgica. Este tipo de imagen forma parte de la serie Centerfolds, en la que simula la fotografía cinematográfica, como si fuese un instante detenido dentro de un film. Mismo fenómeno ocurre con la serie Untitled film stills, donde vemos escenas ficticias, aunque inspiradas en la estética de directores como el británico Alfred Hitchcock (1899-1980), el cine negro y el neorrealismo italiano. Las mujeres representadas en Centerfolds son víctimas del abuso masculino, de quienes las abandonan, las maltratan, etc.

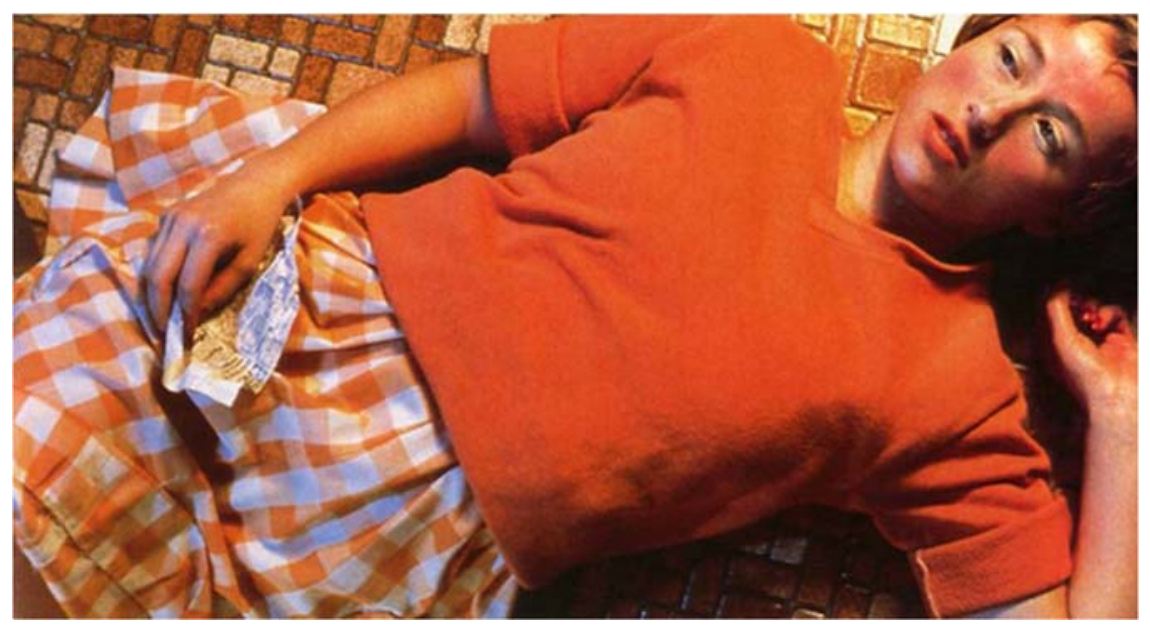

Figura 4. Cindy Sherman. "Untitled \#96". Fotografía análoga. 1981. 
Morimura, por su parte, al citar esta fotografía de Sherman (fig.5), genera una doble apropiación, ya que imita a una imitadora y de un modo bastante similar, cual homenaje a la fotógrafa y performer estadounidense, visible en el título de su obra: "To my little sister, for Cindy Sherman". No obstante, en la foto de Morimura se percibe menos espontánea la expresión del rostro; mientras que en Sherman vemos una imagen verosímil, eventualmente sacada de una película, el artista japonés evidencia de manera sutil el artificio de la actuación a través de su tensión y su mueca facial.

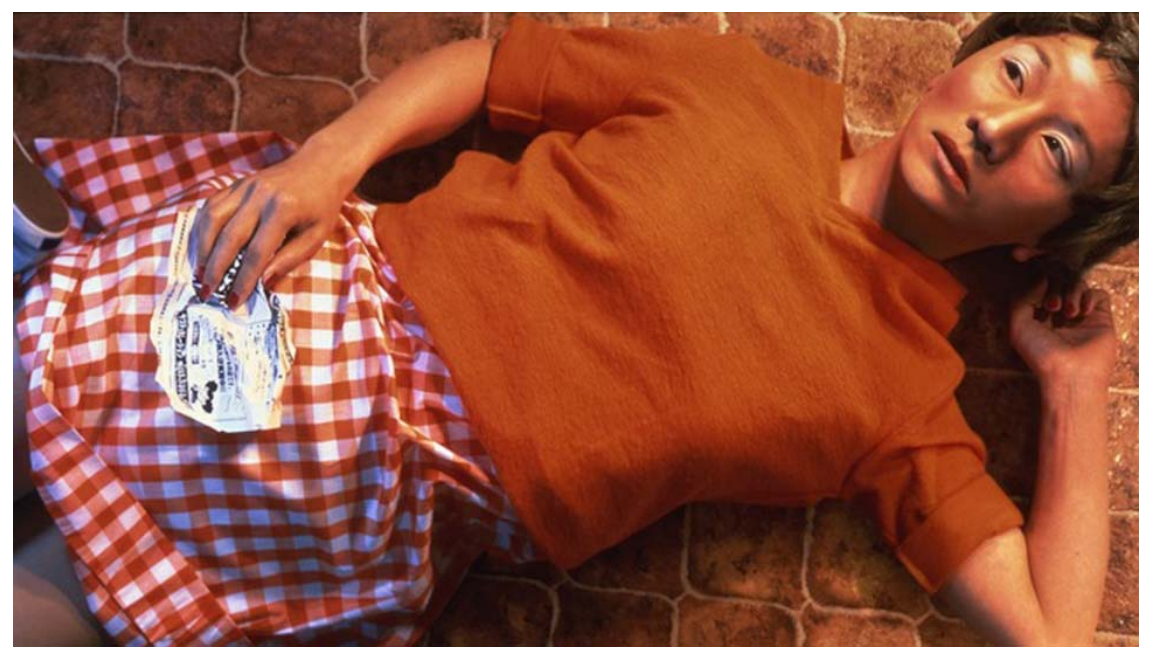

Figura 5. Yasumasa Morimura. "To My Little Sister: for Cindy Sherman". Fotografía análoga. 1998.

Otro ejemplo que citar del artista japonés es su autorretrato en blanco y negro a lo Marilyn Monroe (fig.6) del año 1996. En este retrato de busto, vemos nuevamente a Morimura disfrazado, esta vez como Marilyn, recreando sus atuendos, sus accesorios, su maquillaje y su pose. Se trata de una parodia a la belleza femenina, sus modelos y estereotipos reflejados en la famosa actriz, ícono de belleza y sensualidad en el siglo XX. La parodia la podemos notar, al igual que en la foto anterior, en la expresión facial del artista, cuya ironía intrínseca explicita la intencionalidad paródica y burlesca, además de carecer de la iluminación frontal y posterior que rodea a Marilyn en su retrato cual diosa luminosa. Aquí en cambio, no hay Marilyn ni "diosa" sino un hombre travestido; artificial sustituto de quien fuera alguna vez una mujer joven, sexy y guapa dentro del estándar mediático occidental. Aún así, el artista nos plantea ciertas interrogantes mediante sus recreaciones: ¿es posible la belleza en la reproducción e inversión de sexo que presenta su obra? ¿Puede Morimura igualar o competir con la belleza de Marilyn Monroe? Cuestiones que no son obvias ni fáciles de responder, pues van ligadas 
a constructos culturales, variables siempre de acuerdo con el lugar y el contexto histórico.

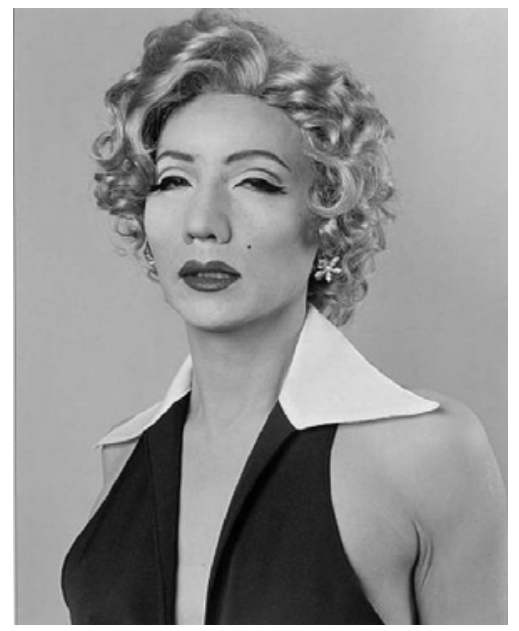

Figura 6. Yasumasa Morimura. "After Marilyn Monroe". Fotografía análoga. 1996.

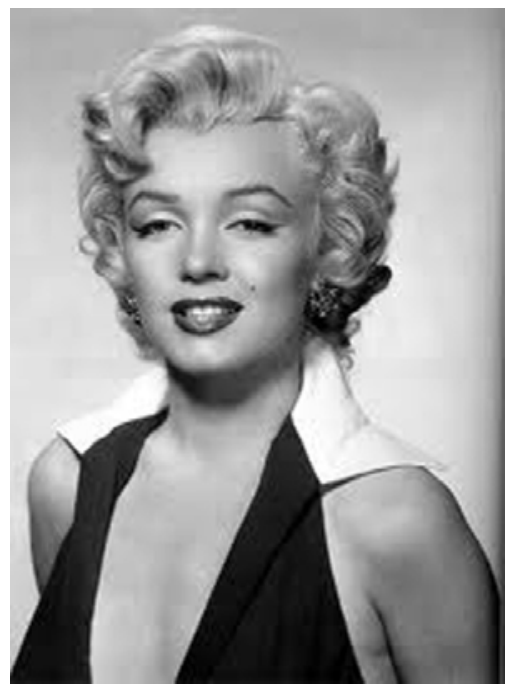

Figura 7. Retrato de Marilyn Monroe. Fotografía análoga. 1953.

Tales nociones quedan explícitamente expuestas en su obra "Black Marilyn" de 1996 (fig.8). Allí aparece Morimura ya no imitando a una foto puntual de Marilyn, pero sí su pose y su apariencia. Lo vemos de pie sobre un plinto, con un escotado traje y tacos, todo de color negro, inclusive el fondo. El concepto de feminidad, sensualidad y erotismo que portaba la actriz queda puesto en jaque cuando 
vemos al artista oriental exhibiendo un exagerado vello púbico y un falo erecto bajo la falda, como era usual, volándose al viento, la que él a su vez levanta un poco, al tiempo que se toca levemente un pecho. Sin embargo, en lugar de ver las formadas piernas de la joven, nos encontramos con los no disimulados miembros masculinos, por lo demás artificiales y exacerbados. Este gesto visibiliza la caricatura y la ironía paródica en torno a las problemáticas ya señalas: el travestismo del cuerpo, la condición de feminidad, de masculinidad, la belleza, la sensualidad, el erotismo y sus estereotipos dentro de los marcos culturales, en este caso, occidentales.

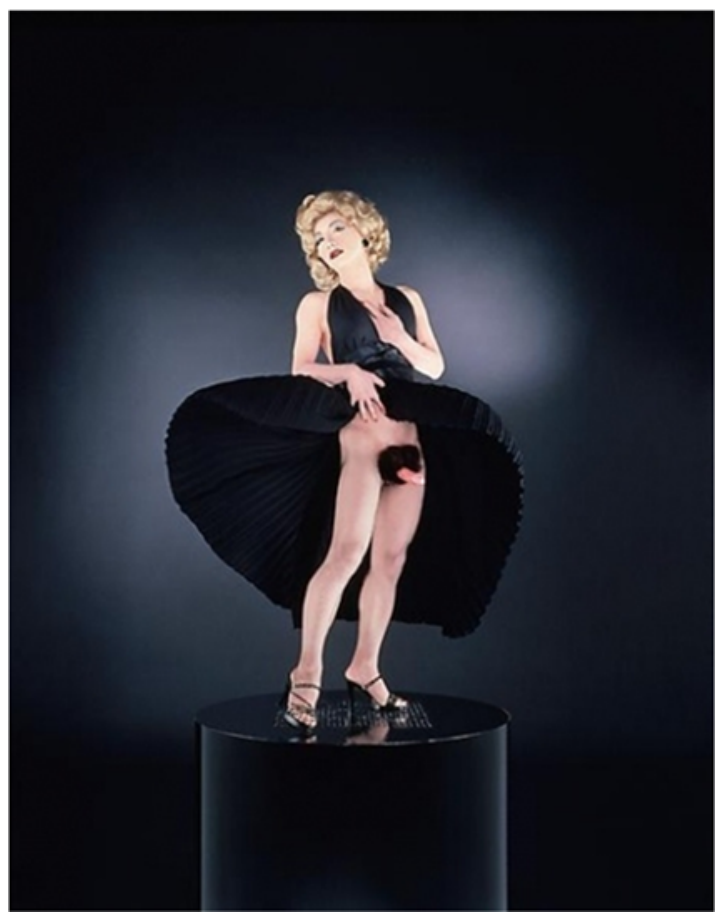

Figura 8. Yasumasa Morimura. "Black Marilyn". Fotografía análoga. 1996.

\section{Algunas conclusiones}

Por último, podríamos señalar que la parodia en sí contiene al anacronismo. Si bien la primera alude al gesto irónico dentro de una imitación o cita, con el fin de manifestar una crítica frente a determinados constructos sociales, políticos, etc.; el anacronismo, en cambio, es la yuxtaposición de tiempos dentro de un mismo relato/objeto/obra. Aún así, coexisten ambos términos en la medida que no es 
posible pensar la parodia en el arte contemporáneo aislada de todo orden temporal. La parodia, en efecto, vincula dos o más temporalidades en tanto momentos históricos que van asociados a ciertos contextos, y son éstos los que en última instancia son puestos en tensión para ser parodiados. Se requiere, así, un conocimiento respecto al objeto y su consecuente contexto parodiado para que un artista pueda apropiárselo adecuadamente y lograr subvertir algún elemento presente. En este sentido, existe una crisis ante el relato moderno de la pureza, mencionada al inicio del ensayo, pues, con la recreación paródica, se pone en duda esta idea de obra única, original y eterna, que se preocupa únicamente del arte mismo y su representación. De partida, la obra que parodia se basa en una ya existente, por ende, pierde de inmediato esa condición de creatividad absoluta acaso inexistente. Sin embargo, sí es única en tanto hay una apropiación por parte de un artista -Morimura, en este caso-, cuya diferencia conceptual y de tratamientos hace la novedad; en la mirada crítica que pueda contener la nueva obra y sus formas para lograr dialogar un tiempo con otro. De este modo, la parodia mantiene su carácter crítico, en la medida en que no es una cita a secas o mera imitación de otra obra. Efectivamente, es una cita, pero con una ironía subyacente que busca tensionar dos realidades y tiempos, causando un contrapunto que cuestiona la veracidad o validez actual de la obra citada, evaluando cómo se manifiesta y (dis)continúa en la contemporaneidad.

La utopía moderna frente a lo nuevo se desmonta al expandir la referencialidad en el momento de crear: los referentes yacen en todas partes, tanto en otros artistas como en la cultura y en la vida misma, que es dinámica. Ante la pregunta por lo real o verdadero, la posmodernidad no puede ya vislumbrar un destino único, volviéndose necesario este retorno y mixtura de tiempos y relatos que se reconfiguran y cuestionan cada vez, por ejemplo, mediante el arte. No tiene sentido despachar el pasado ni la memoria; por el contrario, son éstos los que contribuyen al discurso heterogéneo, múltiple y disensual que yace hace años y que, como diría Rancière, redefine el paisaje de lo visible/factible. Es en ese contexto donde afloran artistas como Yasumasa Morimura o la citada Cindy Sherman, entre muchos otros, quienes exploran a través de sus propios cuerpos la noción de identidad, sus márgenes y posibilidades en un mundo donde aún prevalecen ciertas consignas sobre lo femenino-masculino, lo hombre-mujer, occidental-oriental, lo global-local, etc.

Por ende, el trabajo de Morimura es más que una cita u homenaje a la historia del arte, la cultura y sus "representantes"; es una parodia frente a los estereotipos artísticos y sociales, muchas veces naturalizados. De esta manera es que este artista expone su cuerpo como un espacio de convergencia sexual, temporal y cultural, más allá de los marcos del pudor, la belleza y la heteronorma del presente, pues no es Yasumasa Morimura a quien vemos -en estricto rigor- en las 
fotografías, sino a un personaje. Y es allí, a través de aquel montaje y puesta en escena fotográfica con pintura, atuendos y objetos, donde se anuncia el artificio y la construcción de imagen, que es también construcción identitaria y, finalmente, política-social.

\section{Referencias}

Bataille, G. (2002). Las lágrimas de Eros. Barcelona: Tusquets.

Baudrillard, J. (2007). El complot del arte. Ilusión y desilusión estéticas. Buenos Aires: Amorrortu.

Cubo, Ó. (2010). Hegel y el fin del arte. HYBRIS 2(1). 6-19. Recuperado el 10 de noviembre de 2017 de http://revistas.cenaltes.cl/index.php/hybris/article/view/10/10.

Danto, A. (1999). Después del fin del arte. España: Paidós.

Didi-Huberman, G. (2011). Ante el tiempo: historia del arte y anacronismo de las imágenes. Buenos Aires: Adriana Hidalgo.

Eco, U. (2007). Historia de la fealdad. Barcelona: Lumen.

García Canclini, N. (2001). Culturas hibridas. Estrategias para entrar y salir de la modernidad. Argentina: Paidós.

Hutcheon, L. (1985). El alcance pragmático de la parodia. A Theory of Parody. The Teachings of Twentieth-Century Art Forms. Recuperado el 10 de diciembre de 2016 de https://es.scribd.com/document/215596143/Capitulo-3-de-Una-teoria-de-la-parodia-de-Hutcheon.

Hutcheon, L. (1993). La política de la parodia posmoderna. Criterios, julio. 187-203.

Jameson, F. (1991). El posmodernismo o la lógica cultural del capitalismo avanzado. Barcelona: Paidós. 